\title{
Announcements
}

\section{CALL FOR PAPERS:}

\section{A SPECIAL ISSUE ON HISTORICAL STUDIES OF DREAMING}

Dreaming is planning a special issue on historical studies of dreams scheduled for publication in early 2000. Contributions are invited for articles that (1) examine the role of dreams in a particular historical setting or cultural milieu; (2) analyze what a specific historical figure or text said about dreams; (3) compare the place of dreams in different historical eras and, if applicable, track developments from one era to another; (4) survey the changing view of dreams and dreaming through the history of religion, philosophy, literature, and/or science; (5) examine the historical development of various clinical applications of dreams, including historical literature reviews on the role of dreams in differing diagnostic groups and the use of dreams in specific therapeutic traditions. Manuscripts will undergo full peer review and should be submitted by 1 March 1999 to:

Hendrika Vande Kemp, Ph.D, 180 N. Oakland Avenue, Pasadena, CA 911011714, U.S.A.

or

Kelly Bulkeley, Ph.D., 226 Amherst Avenue, Kensington, CA 94708, U.S.A.

\section{JOIN THE ASD}

For information on how to join the Association for the Study of Dreams, you can:

- write to Membership Chair, ASD, Box 1600, Vienna, VA 22183, U.S.A.

- $\quad$ call (703)242-0062

- $\quad$ fax (703)242-8888

- email ASDreams@aol.com OR

- visit the ASD website at http://www.ASDreams.org/ 